ORIGINAL ARTICLE

\title{
Leptin responses to short term exercise in college level male rowers
}

\section{J Jürimäe, T Jürimäe}

Br J Sports Med 2005;39:6-9. doi: 10.1136/bjsm.2003.008516

See end of article for authors' affiliations

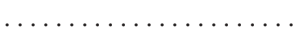

Correspondence to: Dr Jürimäe, Institute of Sport Pedagogy and Coaching Sciences, University of Tartu 18 Ulikooli St, Tartu 50090 , Estonia; jaakj@ut.ee

Accepted

2 December 2003
Objective: To investigate plasma leptin response to short term exercise in college level male rowers. Methods: Thirteen rowers performed a 30 minute maximal rowing ergometer test. Venous blood samples were obtained before, immediately after, and after 30 minutes of recovery. Concentrations of leptin, insulin, growth hormone, insulin-like growth factor-I (IGF-I), and IGF binding protein-3 (IGFBP-3) were measured.

Results: Plasma leptin was significantly $(p<0.05)$ decreased (from a mean (SD) of $2.7(0.6)$ to 2.1 $(0.8) \mathrm{ng} / \mathrm{ml}$ ) and growth hormone significantly increased (from $0.6(0.9)$ to $4.6(5.4) \mu \mathrm{lU} / \mathrm{l}$ ) immediately after the 30 minute maximal rowing exercise session (distance covered 7870.4 (443.3) m; blood lactate immediately after the test 14.9 (4.3) mmol/l). All other blood variables measured were not significantly changed as a result of the ergometer test. A positive relation was observed between the decreased plasma leptin concentration immediately after the test and the distance covered $\left(R^{2}=0.645 ; p<0.05\right)$. Changes in leptin and IGF-I concentrations immediately after the test were also related $\left(R^{2}=0.390 ; \mathrm{p}<0.05\right)$. Percentage body fat explained $89.6 \%(p<0.05)$ of the variance $\left(R^{2} \times 100\right)$ in basal leptin concentration. After normalisation for body fat, basal leptin was related $(p<0.05)$ to basal insulin $(r=0.82)$ and training history $(r=-0.60)$.

Conclusion: Leptin is sensitive to relatively short term intense exercise when all major muscles are involved.
L eptin may be a nutrient sensing signal of adipose and muscle tissue; it is thought to be the missing link between adipose tissue and certain systems regulating body mass and energy expenditure. ${ }^{1}$ Its major role is to relay information on the status of energy stores to signal transducing receptors in the hypothalamus, ${ }^{2}{ }^{3}$ thus regulating eating. ${ }^{1}$ The greater the amount of adipose tissue present, the more leptin is produced and released into the circulation. ${ }^{3}{ }^{4}$ The role of leptin in the regulation of energy homoeostasis has been the focus of several investigations. ${ }^{25}$

Exercise is a potent stimulus for secretion of many hormones, ${ }^{67}$ and exercise mediated negative energy balance may contribute to the regulation of plasma leptin concentrations. ${ }^{25}$ Although prolonged physical activity has been reported to reduce plasma leptin concentrations, ${ }^{89}$ the effect of physical activity, independently of loss of body fat mass, has not yet been clearly established. ${ }^{2}{ }^{4}$ However, recent studies have shown that endurance exercise with marked negative energy balance-for example, marathon swimming, marathon running-may cause an immediate or delayed decrease in leptin concentration. $^{21011}$ In contrast, short term ( $\leqslant 30$ minutes) exercise studies suggest that leptin concentration is not acutely affected by exercise regardless of intensity, ${ }^{2}{ }^{4}$ as the exercise mediated energy expenditure may not reach the critical level needed for plasma leptin concentrations to be reduced by acute exercise. ${ }^{5}{ }^{12}$ In addition, these short term exercise studies have used exercise protocols in which only the lower extremities were involved-that is, running or cycling. ${ }^{4}$ To our knowledge, no studies have yet investigated the effect of short term maximal exercise on plasma leptin using an exercise protocol in which all major muscle groups are involved. Therefore we evaluated the effects of 30 minutes of maximal ergometer rowing on plasma leptin in male rowers. We hypothesised that maximal ergometer rowing would have an impact on plasma leptin concentrations, as rowers have relatively large body masses and all extremities and trunk muscles are involved in rowing. ${ }^{67}$

\section{MATERIALS AND METHODS \\ Study design}

Thirteen male college level rowers volunteered. They had trained regularly for the preceding 5.8 (1.9) years (mean $(\mathrm{SD}))$. Measurements were performed during the preparatory period. ${ }^{9}$ The participants trained 4.5 (2.9) times a week throughout the year. They were fully familiarised with the procedures before providing their written consent to participate in the experiment, as approved by the medical ethics committee of the University of Tartu. First, each subject completed body composition and performance assessment tests. The second measurement session consisted of a 30 minute maximal test on a rowing ergometer to determine leptin responses to relatively short term exercise. ${ }^{2}$ The two sessions were separated by at least one week. The rowers were asked not to participate in any physical activity in the 24 hours before each session. ${ }^{7}$

\section{Assessment of body composition}

The height (Martin metal anthropometer) and body mass (A\&D Instruments Ltd, Abingdon, Oxfordshire, UK) of the participants were measured to the nearest $0.1 \mathrm{~cm}$ and $0.05 \mathrm{~kg}$ respectively. Body composition was measured using dual energy $x$ ray absorptiometry. Scans of the whole body were performed on each of the subjects using a Lunar DPX-IQ scanner (Lunar Corporation, Madison, Wisconsin, USA), ${ }^{13}$ and analysed for fat and fat free mass.

\section{Exercise tests}

Exercise tests were performed on a rowing ergometer (Concept II, Morrisville, North Carolina, USA) at the same time of day (between 1100 and 1300), and the time of the test was identical for each subject across both tests. All subjects had eaten a meal about two hours before the test. ${ }^{71}$ During

Abbreviations: IGF-I, insulin-like growth factor-I; IGFBP-3, IGF-binding protein-3 
the rowing performance test, the rowers were asked to cover a distance of $2000 \mathrm{~m}$ in the least time possible. ${ }^{6} 9$ The second exercise test was a 30 minute maximal rowing ergometer test, and the distance covered was considered to be the total work performed. ${ }^{7}$ Heart rates were recorded during both exercise tests using Sporttester Polar Vantage NV (Kempele, Finland). ${ }^{67}$

\section{Blood analysis}

A $10 \mathrm{ml}$ blood sample was obtained from an antecubital vein, with the subject in the upright position, before, immediately after, and 30 minutes after the maximal rowing ergometer test. $^{7}$ Similarly to other recent studies, no control trial was conducted, as diurnal changes in measured hormones were considered not to occur during this short time period..$^{2}{ }^{14}$ The plasma was separated and frozen at $-20^{\circ} \mathrm{C}$ for later analysis. Leptin was determined in duplicate by radioimmunoassay (Milenia Biotec GmbH, Bad Nauheim, Germany). This assay has a detection limit of $0.01 \mathrm{ng} / \mathrm{ml}$, and intra-assay and interassay coefficients of variation of $<5 \%$ and $<7.5 \%$ respectively. ${ }^{9}{ }^{15}$ Insulin, growth hormone, insulin-like growth factor-I (IGF-I), and IGF-binding protein-3 (IGFBP-3) were determined in duplicate on Immulite 2000 (DPC, Los Angeles, California, USA). The intra-assay and interassay coefficients of variation for insulin were $4.5 \%$ and $12.2 \%$ respectively at an insulin concentration of $6.6 \mu \mathrm{IU} / \mathrm{ml}$. The intra-assay and interassay coefficients of variation for growth hormone, IGF-I, and IGFBP-3 were less than 7\%. All samples were run on the same assay. Glucose was measured by the hexokinase/glucose-6-phosphate-dehydrogenase method with a commercial kit (Boehringer, Mannheim, Germany). Blood lactate was determined enzymatically (Lange, Diessen, Germany). ${ }^{7}$ Aliquots of whole blood were also analysed in quadruplicate for packed cell volume at $12000 \mathrm{rpm}$ for five minutes and for haemoglobin using a Lange microanalyser. Changes in plasma volume after exercise were calculated using the formulae of Dill and Costill. ${ }^{16}$

\section{Statistical analysis}

Means (SD) were determined. Friedman analyses of variance by ranks were used to examine changes, as the row data and their logarithmic transformations were not normally distributed. The Wilcoxon matched pairs signed ranks test was used where post hoc analysis was relevant. Regression analyses, Spearman correlation, and partial correlation coefficients were used to evaluate associations among different variables. Statistical significance was accepted at $\mathrm{p}<0.05$.

\section{RESULTS}

Table $\mathrm{l}$ presents the subject characteristics. The $2000 \mathrm{~m}$ rowing ergometer performance time (406.5 (15.8) seconds) was found to correspond to a mean heart rate of 184 (7) beats/min. The distance covered during the 30 minute maximal rowing ergometer test was $7870.4(443.3) \mathrm{m}$ with a mean heart rate of 175 (9) beats/min or $95.1(2.2) \%$ of the mean heart rate obtained during maximal $2000 \mathrm{~m}$ rowing

\begin{tabular}{|c|c|c|}
\hline Variable & Mean (SD) & Range \\
\hline Age (years) & $22.8(4.5)$ & $18.0-32.0$ \\
\hline Height $(\mathrm{cm})$ & $186.7(4.8)$ & $180.0-192.0$ \\
\hline Body mass $(\mathrm{kg})$ & $83.5(8.5)$ & $73.2-102.9$ \\
\hline Body fat (\%) & $13.3(5.8)$ & $7.1-19.2$ \\
\hline Fat mass (kg) & $11.0(6.1)$ & $5.7-19.8$ \\
\hline Fat free mass $(\mathrm{kg})$ & $72.4(8.6)$ & $66.0-83.1$ \\
\hline
\end{tabular}

ergometer test. Blood lactate concentration before the 30 minute maximal rowing ergometer test was 1.8 (0.4) $\mathrm{mmol} / \mathrm{l}$, which was significantly increased immediately

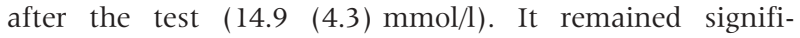
cantly raised after the first 30 minutes of recovery $(4.8$ (1.3) $\mathrm{mmol} / \mathrm{l})$. Plasma volume was reduced immediately after the ergometer test $(-4.7 \quad(5.4) \% ; \mathrm{p}<0.05)$. After 30 minutes of recovery, it had almost returned to baseline values $(-0.1(4.9) \%)$

The concentration of leptin and growth hormone were significantly decreased and increased respectively immediately after the maximal 30 minutes of ergometer rowing (table 2). Leptin concentration remained significantly reduced after 30 minutes of recovery. No significant changes were noted in other blood variables measured immediately after the test and after the first 30 minutes of recovery.

Regression analysis showed a positive relation between significantly decreased plasma leptin concentration immediately after the 30 minutes of maximal ergometer rowing and the distance covered $\left(R^{2}=0.645 ; \mathrm{p}<0.05\right)$. In addition, changes in plasma leptin concentrations were related to changes in IGF-I concentrations immediately after the test $\left(R^{2}=0.390 ; \mathrm{p}<0.05\right)$. There were no correlations between plasma leptin and other measured blood variables immediately after the test, nor were changes in leptin related to changes in other measured blood biochemical values after the test.

According to the regression analysis, percentage body fat explained $89.6 \%\left(R^{2} \times 100 ; \mathrm{p}<0.05\right)$ of the variance in basal leptin concentration. Basal leptin correlated significantly only with resting body mass $(r=0.64)$ and plasma insulin $(r=$ 0.88 ). After normalisation for body fat, the relation between leptin and body mass was no longer significant (table 3). However, the relation between leptin and insulin remained positively correlated. In addition, basal leptin concentration was related to the training history after normalisation for body fat.

\section{DISCUSSION}

The main purpose of the present study was to find possible effects of 30 minutes of acute exercise ${ }^{2}{ }^{4}$ on leptin concentration in college level male rowers. Most previous studies on the effects of short term exercise on leptin have shown no change in leptin concentration regardless of exercise intensity in healthy men and women. ${ }^{2}{ }^{4}$ Furthermore, Kraemer et al argued that the absence of any reduction in leptin found in short term exercise studies may be due to the limited energy expenditure during these exercise bouts and/or the exercise protocol. However, our study was designed to overcome these limitations in that the subjects were rowers, who have relatively large body masses, and all extremities and trunk muscles are involved in rowing. ${ }^{67}$ Furthermore, in contrast with this study, previous studies have used exercise protocols

Table 2 Changes in blood biochemical variables during 30 minutes of maximal rowing on an ergometer in male rowers

\begin{tabular}{|c|c|c|c|}
\hline Variable & Before & After & After $30 \mathrm{~min}$ \\
\hline $\mathrm{g} / \mathrm{ml})$ & ) & $.8)^{*}$ & $.9)^{*}$ \\
\hline $\begin{array}{l}\text { Growth hormone } \\
(\mu \mathrm{IU} / \mathrm{I})\end{array}$ & 0.610 & $.6(5.4)^{*}$ & $1.9(2.7)$ \\
\hline Insulin ( $\mu \mid U / I)$ & $8.8(6.9)$ & $6.8(2.7)$ & $6.2(4.1)$ \\
\hline IGF-I ( $\mu \mathrm{g} / \mathrm{l})$ & $232.6(100.0)$ & $251.1(59.0)$ & $181.7(157.6)$ \\
\hline IGFBP-3 ( $\mu \mathrm{g} / \mathrm{I})$ & $4281.4(766.1)$ & $4482.4(402.2)$ & $3961.5(1039.3)$ \\
\hline Glucose (mmol/l) & $4.5(0.5)$ & $4.3(0.6)$ & $4.4(0.6)$ \\
\hline
\end{tabular}

Values are mean (SD).

*Significantly different from before exercise; $\mathrm{p}<0.05$.

IGF-I, insulin-like growth factor-l; IGFBP-3, IGF binding protein-3. 
Table 3 Relations between basal leptin normalised for body fat and body composition and blood biochemical variables in male rowers

\begin{tabular}{lr}
\hline Basal leptin $(\mathrm{ng} / \mathrm{ml}) \boldsymbol{v}$ & $\boldsymbol{r}$ Value \\
\hline Age (years) & $-0.32(0.20)$ \\
Training history (years) & $-0.60(0.04)$ \\
Body mass $(\mathrm{kg})$ & $0.31(0.21)$ \\
Fat free mass $(\mathrm{kg})$ & $0.01(0.49)$ \\
Rowing performance (seconds) & $0.01(0.49)$ \\
Exercise energy expenditure $(\mathrm{m})$ & $0.12(0.38)$ \\
Growth hormone $(\mu \mathrm{IU} / \mathrm{I})$ & $0.11(0.77)$ \\
Insulin $(\mu \mathrm{IU} / \mathrm{I})$ & $0.82(0.01)$ \\
IGF-I $(\mu \mathrm{g} / \mathrm{l})$ & $-0.33(0.39)$ \\
IGFBP-3 $(\mu \mathrm{g} / \mathrm{l})$ & $-0.26(0.50)$ \\
Glucose $(\mathrm{mmol} / \mathrm{I})$ & $0.23(0.54)$ \\
\hline
\end{tabular}

Values in parentheses are $p$ values.

Rowing performance, $2000 \mathrm{~m}$ "all out" rowing ergometer performance time; exercise energy expenditure, maximal distance covered during

30 minutes of rowing; IGF-I, insulin-like growth factor-I; IGFBP-3, IGF binding protein-3.

in which only lower extremities were involved-that is, running or cycling. ${ }^{2414}$ To our knowledge, this is the first study to investigate the effects of short term exercise on leptin concentration using a design in which the major muscle groups of the whole body are working. Accordingly, the main finding of this study was that leptin was significantly decreased immediately after the 30 minutes of maximal rowing ergometer exercise in college level male rowers. Furthermore, the distance covered was significantly related to leptin concentration immediately after the exercise.

The distance covered explained $64.5 \%(\mathrm{p}<0.05)$ of the variance $\left(R^{2} \times 100\right)$ in post-exercise plasma leptin concentration. This shows that the total work output during this exercise session was above the threshold reduction in energy availability that must be reached to alter the leptin concentration. $^{512}$ Indeed, the blood lactate concentration immediately after 30 minutes of maximal ergometer rowing was very high ( $14.9(4.3) \mathrm{mmol} / \mathrm{l})$ and remained significantly raised for the first 30 minutes of recovery $(4.8$ (1.3) $\mathrm{mmol} / \mathrm{l})$, indicating high metabolic effort. ${ }^{6}$ In addition, the raised blood lactate concentrations show that the 30 minutes of rowing was highly anaerobic. It is known that anaerobic activity results in greater energy expenditure as a result of acute exercise. ${ }^{411}$ In contrast, Weltman et al showed that acute treadmill exercise for 30 minutes at, above, and below the lactate threshold did not alter leptin concentration in young men. Thus the sustained anaerobic nature of the exercise in our study may explain the significant reductions in leptin concentration immediately after the test.

It can be speculated that the data presented here (table 2) show that the amount of muscle tissue used during a short term exercise bout can also influence the leptin response. It is well known that about $70 \%$ of whole body muscle mass is involved in rowing, ${ }^{67}$ and the energy expended during 30 minutes of maximal ergometer rowing was enough to cause changes in leptin concentration in sportsmen with relatively high body fat (percentage body fat 13.3 (5.8)). The results of our study show that leptin could be used as a biological marker of physical stress after acute high intensity short term exercise in rowers, who use all the major muscle groups of the body during rowing.

Plasma leptin concentrations have usually been corrected for changes in plasma volume after the exercise session, ${ }^{17}{ }^{18}$ as a decrease in plasma volume could increase the value. However, it may be the concentration of the hormone at the target tissues that is of importance, regardless of how the change in concentration is established. ${ }^{7}$ In these studies, ${ }^{17}{ }^{18}$ leptin concentrations were corrected by applying
What is already known on this topic

Leptin is reduced at a certain negative energy balance. Decreased leptin has been observed immediately after prolonged exercise.

\section{What this study adds}

Leptin was decreased immediately after short term maximal rowing. This study is different from previous work in that rowing uses all the major muscles of the body.

a mathematical formula for haemoconcentration. ${ }^{16}$ Similarly to other short term exercise studies, ${ }^{2}{ }^{4}$ we made no corrections to the plasma leptin concentrations after the rowing ergometer test. There was a mean $4.7 \%$ reduction in plasma volume during the exercise session. However, during the first 30 minutes of recovery, it returned to the baseline value. This further confirmed that the significantly decreased leptin concentration after exercise observed in our study was due to alterations in leptin mass rather than changes in haemoconcentration.

Similarly to the results of other studies with different athletes, $^{9-11} 15$ basal leptin in these male college level rowers was relatively low. An interesting finding of this study is that the training history of the subjects was significantly related to the circulating leptin concentration normalised for body fat $(r=-0.60 ; \mathrm{p}<0.05)$. This further confirms the independent effect of chronic physical activity on plasma leptin concentration. ${ }^{5}{ }^{915}$ In accordance with this, it has been suggested that leptin concentrations are reduced after 10 months of endurance type training in obese men, independent of body fat. ${ }^{19}$

The primary regulator of leptin $(o b)$ gene expression and secretion is adiposity, ${ }^{25}$ as also shown in this study $\left(R^{2}=\right.$ $0.896 ; \mathrm{p}<0.05)$. However, acute and chronic changes in energy balance can disproportionately downregulate or upregulate leptin secretion respectively..$^{21}$ It has been argued that the diurnal rhythm of leptin is not dependent on energy intake or expenditure ${ }^{21}$ but rather on energy and/or carbohydrate availability. ${ }^{12}$ Increasing evidence supports the notion that insulin may be a critical regulator of $o b$ gene expression and is a leptin secretagogue. ${ }^{21}$ Thus insulin may provide a mechanism by which adipose tissue detects changes in overall energy balance, and, in turn, upregulates or downregulates $o b$ gene expression accordingly. ${ }^{21}$ Similarly to other investigations, ${ }^{1521}$ a significant correlation between leptin and insulin $(r=0.88 ; \mathrm{p}<0.05)$ was found in this study, and this was evident even after normalisation for body fat $(r=$ $0.82 ; \mathrm{p}<0.05)$. Thus the relation between basal leptin and insulin concentrations appears to be independent of adipose tissue in college level male rowers.

The effect of an insulin dependent mechanism on leptin was also confirmed by stepwise regression, as we found that a post-exercise IGF-I concentration explained 39.0\% $(\mathrm{p}<0.05)$ of the variance $\left(R^{2} \times 100\right)$ in significantly decreased leptin concentration immediately after the 30 minutes of maximal ergometer rowing. This is in accordance with the study of Elias et al, ${ }^{14}$ who argued that the decline in plasma leptin concentrations immediately after acute exercise to exhaustion may be related to the increased IGF-I concentrations in male unconditioned volunteers. However, in contrast with previous studies, ${ }^{22}$ changes in growth hormone concentrations did not affect changes in leptin concentration as a 
result of short term maximal ergometer rowing exercise in male college level rowers. This is in line with the findings of Weltman et al, ${ }^{4}$ who also suggested that the growth hormone response to acute exercise is not mediated through leptin as a metabolic signal. In addition, it has been suggested that IGF-I and IGFBP-3 responses to acute exercise seem to be unrelated to growth hormone responses. ${ }^{23}$ Furthermore, Sonksen ${ }^{24}$ argues that circulating IGF-I should be considered more as a marker of growth hormone action rather than a mechanism by which growth hormone exerts its effects. However, further studies are needed to determine the individual roles of specific hormones that influence leptin concentration as a result of physical exercise.

In summary, this study shows that circulating plasma leptin is lowered as a result of 30 minutes of maximal rowing ergometer exercise in which all major body muscles are involved. The total amount of mechanical work performed by the muscles explained $64.5 \%$ of the post-exercise plasma leptin concentration. It is suggested that plasma leptin could be used as a biological marker of physical stress after short term $(\leqslant 30$ minutes) high intensity exercise when the total work output is above the threshold reduction in energy availability.

\section{Authors' affiliations}

J Jürimäe, T Jürimäe, Institute of Sport Pedagogy and Coaching Sciences, University of Tartu, Tartu, Estonia

Conflict of interests: none declared

\section{REFERENCES}

1 Campfield LA, Smith FJ, Guisez J, et al. Recombinant mouse OB protein: evidence for a peripheral signal linking adiposity and central neural networks. Science 1995;269:546-9.

2 Kraemer RR, Chu H, Castracane VD. Leptin and exercise. Exp Biol Med 2002;227:701-8.

3 Gomez JM, Maravall FJ, Gomez N, et al. Pituitary-thyroid axis, thyroid volume and leptin in healthy adults. Horm Metab Res 2002;34:67-71.

4 Weltman A, Pritzlaff CJ, Wideman L, et al. Intensity of acute exercise does not affect serum leptin concentrations in young men. Med Sci Sports Exerc 2000;32:1556-61.
5 Hickey MS, Calsbeck DJ. Plasma leptin and exercise. Recent findings. Sports Med 2001:31:583-9.

6 Jürimäe J, Jürimäe T. Responses of blood hormones to the maximal rowing ergometer test in college rowers. J Sports Med Phys Fitness 2001;41:73-7.

7 Jürimäe J, Jürimäe T, Purge P. Plasma testosterone and cortisol responses to prolonged sculling in male competitive rowers. J Sports Sci 2001;19:893-8.

8 Gomez-Merino D, Chennaoui M, Drogou C, et al. Decrease in serum leptin after prolonged physical activity in men. Med Sci Sports Exerc 2002:34:1594-9.

9 Mäesłu J, Jürimäe J, Jürimäe T. Hormonal reactions during heavy training stress and following tapering in highly trained male rowers. Horm Metab Res 2003;35:109-13.

10 Karamouzis I, Karamouzis M, Vrabas IS, et al. The effects of marathon swimming on serum leptin and plasma neuropeptide Y levels. Clin Chem Lab Med 2002:40:132-6

11 Zaccaria M, Ermolao A, Roi GS, et al. Leptin reduction after endurance races differing in duration and energy expenditure. Eur J Appl Physiol 2002;87:108-11

12 Hilton LK, Loucks AB. Low energy availability, not exercise stress, suppresses the diurnal rhythm of leptin healthy young women. Am J Physiol 2000;278:E43-9.

13 De Lorenzo A, Andreoli A, Candeloro N. Within-subject variability in body composition using dual energy X-ray absorptiometry. Clin Physiol 1997; 17:383-8.

14 Elias AN, Pandian MR, Wang L, et al. Leptin and IGF-I levels in unconditioned male volunteers after short-term exercise. Psychoneuroendocrinology 2000;25:453-61

15 Sudi K, Jürimäe J, Payerl D, et al. Relationship between subcutaneous fatness and leptin in male athletes. Med Sci Sports Exerc 2001:33:1324-9.

16 Dill DB, Costill DL. Calculation of percentage changes in volumes of blood, plasma, and red cell in dehydration. J Appl Physiol 1974;37:247-8.

17 Hickey MS, Considine RV, Israel RG, et al. Leptin is related to body fat content in male distance runners. Am J Physiol 1996;272:E938-40.

18 Toriman MC, Zafeiridis A, Paolone AM, et al. Serum leptin during recovery following maximal incremental and prolonged exercise. Int J Sports Med 1999;20:444-50

19 Pasman WJ, Westerterp-Plantenga MS, et al. The effect of exercise training on leptin levels in obese males. Am J Physiol 1998;37:E280-6.

20 Engeli S, Sharma AM. Role of adipose tissue for cardiovascular-renal regulation in health and disease. Horm Metab Res 2000;32:485-99.

21 Thong FS, McLean C, Graham TE. Plasma leptin in female athletes: relationship with body fat, reproductive, nutritional, and endocrine factors. J Appl Physiol 2000;88:2037-44.

22 Kraemer RR, Johnson LG, Haltom RW, et al. Serum leptin concentrations in response to acute exercise in postmenopausal females with and without hormone replacement therapy. Proc Soc Exp Biol Med 1999;221:171-7.

23 Schwarz AJ, Brasel JA, Hintz RL, et al. Acute effect of brief low- and highintensity exercise on circulating insulin-like growth factor (IGF) I, II, and IGFbinding protein-3 and its proteolysis in young healthy men. J Clin Endocrinol Metab 1996;81:3492-7.

24 Sonksen PH. Hormones and sport. Insulin, growth hormone and sport J Endocrinol 2001;170:13-25. 